\title{
Probabilistic encoding of stimulus strength in astrocyte global calcium signals
}

Wayne Croft ${ }^{1}$, Katharina Reusch ${ }^{1,2}$, Agne Tilunaite ${ }^{3}$, Noah A. Russell ${ }^{2}$, Rüdiger Thul ${ }^{3}$, and Tomas C. Bellamy ${ }^{1}$

${ }^{1}$ School of Life Sciences, ${ }^{2}$ Department of Electrical and Electronic Engineering, and ${ }^{3}$ School of Mathematical Sciences, University of Nottingham, Nottingham, NG7 2RD.

Running title: Probabilistic astrocyte calcium signals

Word counts: Abstract: 234; Introduction: 991; Materials and Methods: 944; Results: 3502; Discussion: 1936; Acknowledgments: 47; References: 1688; Legends: 1410.

TOTAL: 10752

Figures: 10

Correspondence to: Dr Tomas C. Bellamy, School of Life Sciences, University of Nottingham Medical School, Nottingham, NG7 2UH. Tel: +44 (0)115 8230539. Email: tomas.bellamy@nottingham.ac.uk

\section{Main points:}

1) Transient stimuli trigger astrocyte calcium waves in a probabilistic manner.

2) Response probability can be modulated by other signalling pathways.

3) Wave initiation follows synchronous calcium release from three or more subcellular "puff" sites.

Keywords: Astrocyte; calcium puffs; crosstalk; ATP; glutamate. 


\begin{abstract}
Astrocyte calcium signals can range in size from subcellular microdomains, to waves that spread through the whole cell (and into connected cells). The differential roles of such local or global calcium signalling are under intense investigation, but the mechanisms by which local signals evolve into global signals in astrocytes are not well understood, nor are the computational rules by which physiological stimuli are transduced into a global signal. To investigate these questions, we transiently applied receptor agonists linked to calcium signalling to primary cultures of cerebellar astrocytes. Astrocytes repetitively tested with the same stimulus responded with global signals intermittently, indicating that each stimulus had a defined probability for triggering a response. The response probability varied between agonists, increased with agonist concentration, and could be positively and negatively modulated by crosstalk with other signalling pathways.

To better understand the processes determining the evolution of a global signal, we recorded subcellular calcium "puffs" throughout the whole cell during stimulation. The key requirement for puffs to trigger a global calcium wave following receptor activation appeared to be the synchronous release of calcium from three or more sites, rather than an increasing calcium load accumulating in the cytosol due to increased puff size, amplitude or frequency. These results suggest that the concentration of transient stimuli will be encoded into a probability of generating a global calcium response, determined by the likelihood of synchronous release from multiple subcellular sites.
\end{abstract}




\section{Introduction}

Astrocyte calcium signalling has emerged in the last few decades as a potential mechanism through which non-excitable glial cells can contribute to information processing in the brain (De Pitta et al. 2012).

Although the computational potential of calcium signalling has been much speculated upon, the basis through which information about neuronal (and vascular) network activity can be encoded into astrocyte calcium signals, and decoded through glial responses, remains uncertain.

Numerous neurotransmitters and hormones have been linked to calcium elevation in astrocytes (Fiacco and McCarthy 2006; Scemes and Giaume 2006; Verkhratsky et al. 1998), and calcium has been shown to regulate many aspects of astrocyte function - from the more "passive" homeostatic roles (Kimelberg 2010), to release of gliotransmitters that can directly modulate neuronal function (Araque et al. 2014). As such, the theory that astrocytes can detect synaptic activity, and respond by modulating neuronal function at an individual and network level has gained currency (Haydon 2001; Ransom et al. 2003). Despite this general consensus, many areas of dispute remain. The most striking current controversy is the equivocal effect of deletion of the type 2 inositol $(1,4,5)$ trisphosphate receptor $\left(\operatorname{InsP}_{3} R\right)$ - which abolishes somatic calcium responses in astrocytes - on the neurophysiological traits that had been hypothesized to depend on neuron-glial communication, such as synaptic plasticity and learning. Some investigators have reported that this intervention does not result in overt defects in synaptic transmission or plasticity (Agulhon et al. 2010; Fiacco et al. 2009), while others have reported deficits (Navarrete et al. 2012; Takata et al. 2011).

This uncertainty has led to a refocussing of attention on the spatiotemporal nature of astrocyte calcium signals (Araque et al. 2014; Rusakov 2015; Srinivasan et al. 2015). Localization of genetic calcium indicators to submembrane regions (Shigetomi et al. 2010), and ultrastructural analysis of astrocyte morphology (Patrushev et al. 2013), have reinforced the view that subcellular calcium signals can be restricted to defined microdomains of the astrocyte, where the receptors and signalling machinery linked to neuron-glial transmission are likely to be localized. As such, a hypothesis is emerging that such local signalling can mediate rapid feedback between the cell types, leading to synaptic modulation, without the need for the calcium increase to spread to a range that encompasses the somatic regions of the cell (Khakh and Sofroniew 2015; Srinivasan et al. 2015). This fits with existing concepts of the hierarchy of calcium signals (Bootman et al. 1997), where subcellular puffs of calcium summate to trigger a positive feedback process of calcium-induced calcium release from internal stores that generates a cell-wide calcium wave - what we will term a "global" calcium signal.

Despite this proposal for the primacy of local calcium signals for mediating gliotransmission, a good deal of evidence exists for the generation of global (even network-wide) calcium waves in astrocytes under physiological conditions (Ding et al. 2013; Hirase et al. 2004; Nimmerjahn et al. 2009; Wang et al. 2006). These global signals must presumably have a role in physiology, and they must arise from underlying local signalling events. At present, however, the conditions under which global signals evolve from local signals, and whether the global signals are able to encode information about the stimulus that triggered them, is poorly understood.

Existing analyses of the encoding of stimulus strength into global calcium waves have focussed predominantly on how the interval between waves varies with stimulus strength or type. By analogy to neuronal spike trains, these repetitive waves of calcium release from intracellular stores are often termed "calcium spikes" (Skupin et al. 2008). A leading hypothesis is that the frequency of calcium spiking is proportional to the strength of stimulus (Berridge et al. 2003), as exemplified by hepatocytes responding to increasing concentrations of a muscarinic receptor agonist (Woods et al. 1986). A more recent analysis 
explored this mechanism in detail, and demonstrated an exponential relationship between mean interspike interval and agonist concentration (Thurley et al. 2014). These authors concluded that fold changes in the average stochastic period of the interspike interval proved the most robust parameter for encoding changes in the stimulus strength into cellular calcium responses.

In general, however, astrocytes seem poorly equipped to encode stimulus strength into interspike interval, despite their capacity to readily generate oscillations in response to neurotransmitter stimuli (James et al. 2011). Evidence for frequency modulation is weak, and the capacity for information to be encoded in interspike interval (at least for spontaneous calcium signals) is small (Skupin et al. 2008). In some respects, this makes intuitive sense, as exploiting patterns in spike interval as an encoding mechanism requires prolonged stimulation. While this may occur for vasoactive compounds, the time scale for neurotransmitter and neuromodulator signalling is orders of magnitude too fast to allow for multiple calcium waves to be generated from a single stimulus event under normal conditions.

Previous work in our laboratory explored the possibility that the kinetics of the calcium response generated by different transmitters could encode information about the strength or type of stimulus, and reached the conclusion that discrimination on these grounds was not feasible due to the overlap in temporal profiles between different stimuli (James et al. 2011). Here we explore an alternative hypothesis: that the strength of a transient stimulus could be encoded as a probability of generating a global calcium signal from underlying subcellular events. We show a robust concentration-response relationship between agonist concentration and probability of generating a global signal, that the probability varies between transmitters, and that neuromodulators that do not themselves generate calcium responses can act as gain modulators - both positively and negatively - for other transmitters. The origin of this probabilistic response is the requirement for the synchronous release of calcium from subcellular "puff" sites, leading to the initiation of a cell wide wave.

As such, the pattern of global calcium signals in an astrocytic network will be a composite of the type of transmitter released, the concentration of transmitter, duration of transient, and coincidence detection between signalling pathways under the dynamic conditions encountered in vivo. 


\section{Materials and Methods}

\section{Ethics statement}

Experiments were performed in accordance with guidelines outlined in the code of practice for humane killing under Schedule 1 of the UK Home Office Animals (Scientific Procedures) Act 1986. Experiments were performed according to policies on the care and use of laboratory animals of British Home Office and European Community laws and were approved by The University of Nottingham Animal Welfare and Ethical Review Body.

\section{Preparation of cerebellar astrocyte cultures}

Under sterile conditions, neonatal (P1-P2) rat pups were sacrificed by cervical dislocation and decapitation before whole brains were removed. A dissection microscope was used to remove the cerebellum before transferring to separate vessels containing ice cold dissection buffer composed of: $\mathrm{Ca}^{2+}-\mathrm{and} \mathrm{Mg}^{2+}-$ free Hank's HEPES-buffered saline solution (Invitrogen, Paisley, UK), 22 mM glucose, 20 mM HEPES, 100 units. $\mathrm{ml}^{-1}$ penicillin, $100 \mu \mathrm{g} . \mathrm{ml}^{-1}$ streptomycin, $0.1 \mathrm{mM}$ L-serine, $0.5 \mathrm{mM}$ L-glutamine and $1 \mathrm{mM}$ sodium pyruvate ( $\mathrm{pH}$ adjusted to 7.2 with $\mathrm{NaOH}$ ). The meninges and blood vessels were removed using fine forceps before the dissected tissue was chopped finely and dissociated enzymatically in buffer supplemented with $15 \mu \mathrm{g} / \mathrm{ml}$ papain $\left(45 \mathrm{~min}, 37^{\circ} \mathrm{C}\right.$ ). Tissue was then mechanically dissociated via repeated trituration through fire-polished Pasteur pipettes in the presence of $20 \mathrm{mg} / \mathrm{ml}$ DNase in medium containing DMEM (Invitrogen, Paisley, UK), $4500 \mathrm{mg} . \mathrm{I}^{-1}$ glucose, $4 \mathrm{mM}$ L-glutamine, $110 \mathrm{mg}$ L-pyruvate, 10\% foetal bovine serum, 50 $\mu \mathrm{g} / \mathrm{ml} \mathrm{L-proline,} 100$ units. $\mathrm{ml}^{-1}$ penicillin, and $100 \mu \mathrm{g} / \mathrm{ml}$ streptomycin. Cells were plated at a density of $5 \times 10^{4}$ cells/ml on poly-I-lysine coated coverslips, or 96 well plates. Medium was refreshed 24 hours after plating, and every 3-4 days thereafter.

\section{Live cell $\mathrm{Ca}^{2+}$ imaging}

Methods were similar to James et al. (2011). Briefly, astrocytes were loaded with $1 \mu \mathrm{M}$ of the $\mathrm{Ca}^{2+}$ indicator Fluo-4 AM (Invitrogen, Paisley, UK) for $30 \mathrm{~min}$ in buffer containing: $135 \mathrm{mM} \mathrm{NaCl}, 3 \mathrm{mM} \mathrm{KCl,} 10 \mathrm{mM} \mathrm{HEPES}$, $15 \mathrm{mM}$-glucose, $2 \mathrm{mM} \mathrm{MgSO}_{4}$ and $2 \mathrm{mM} \mathrm{CaCl}_{2}$. Subsequently de-esterification of accumulated Fluo-4 AM occurred by leaving cells in buffer for a further $30 \mathrm{~min}$ before transferring to the stage of a Brunell inverted microscope $(10 \times, 0.25$ NA) for WIN 55,212-2 treatment experiments, or an Olympus IX70 inverted microscope $(20 \times, 0.75$ NA objective) for all other treatments. Cells were excited at 450/20 nm (exposure $100 \mathrm{~ms}$, frame rate $1 \mathrm{~Hz}$ ) and fluorescence emission detected at 535/50 nm with an ORCA-ER camera (Hamamatsu, Welwyn Garden City, UK).

For imaging $\mathrm{Ca}^{2+}$ puff events, astrocytes were loaded with $2 \mu \mathrm{M}$ Oregon Green 488 BAPTA-1 AM (Invitrogen, Paisley, UK) for 30 min then de-esterified in buffer for 30 min before transferring to the stage of a Nikon Eclipse Ti inverted microscope (60x, 1.4 NA oil immersion objective). Cells were excited at $470 / 10 \mathrm{~nm}$ with an exposure of $30 \mathrm{~ms}$ and continuously imaged for $60 \mathrm{~s}$. Fluorescence emission of 550/10 $\mathrm{nm}$ was detected with a Zyla 4.2 sCMOS camera (Andor Technology Ltd, Belfast, UK) and recorded in Micromanager (Edelstein et al. 2010). Agonists/modulators were added by manual displacement of bath solution with excess buffer containing agonist/modulator at the indicated concentrations.

\section{Image analysis}


For global $\mathrm{Ca}^{2+}$ imaging data, a time-series analyser plugin to ImageJ (available at http://rsb.info.nih.gov/ij; Wayne Rasband, National Institutes of Health, Bethesda, MD) was used to manually define regions of interest (ROI) centred on the cell nucleus. Mean fluorescence intensity within each ROI was quantified and expressed as the ratio of fluorescence at time $t$ divided by mean intensity for $0-20 \mathrm{~s}$ before addition of agonist $\left(F / F_{0}\right)$. Cells were classified as global responders if mean $F / F_{0}$ increased $>1.045$ fold (at least $3 \mathrm{SD}$ above $F_{0}$ ). Area under the curve $(A \cup C)$ is calculated as the integral of fluorescence intensity during the 3 min time window of agonist stimulation $\left[\left(\mathrm{F} / \mathrm{F}_{0}\right) \cdot \mathrm{s}\right]$. Cells were excluded from analysis if $\mathrm{Ca}^{2+}$ signals occurred before addition of agonist.

For $\mathrm{Ca}^{2+}$ puff imaging data, cells were firstly segmented manually in ImageJ to quantify whole cell mean fluorescence and a circular ROI centred within the nucleus to quantify mean nuclear fluorescence. A bespoke algorithm written using Matlab R2015a (The MathWorks, Inc., Natick, Massachusetts, US) was used to automate the detection of $\mathrm{Ca}^{2+}$ puff events within each cell. Raw data time series images of segmented cells were time-binned such that mean and standard deviation of each pixel was calculated every 5 frames. For each frame of the time-binned image sequence, the difference in pixel intensity to the previous frame was calculated. An individual pixel is defined as a candidate puff region pixel if its difference value to the previous frame is $\geq 1.5 \times$ SD (SD taken from previous frame of time-binned SD values). Puff regions were subsequently identified as the regions where the number of spatially-connected candidate pixels in a single frame was $\geq 16$. A circular ROI (radius $=0.65 \mu \mathrm{m}$ ) is centred on the puff region and mean fluorescence intensity of the ROI expressed as the ratio of fluorescence at time $t$ divided by mean intensity from the first 90 ms before addition of agonist/buffer $\left(F / F_{0}\right)$. Subsequent filtering of puff regions discounts any regions that do not show a reduction in $F / F_{0} \geq 50 \%$ puff amplitude within 750 ms of the detected puff time (to exclude long term trends such as wave initiation). Each region matching these criteria is counted as an individual puff event. Puff area is calculated as pixel count within puff region $\times 0.108$ (pixel to $\mu \mathrm{m}$ conversion factor). A cell is classified as having transitioned to a global wave if $\Delta F / F_{0} \geq 0.045$ relative to baseline and the wave is detectable in the nucleus.

\section{Statistical analysis}

All statistical tests were performed with GraphPad Prism ${ }^{\mathrm{TM}}$ software (GraphPad Software Inc., La Jolla, USA). The test applied, numbers of cells, and $p$ values are reported in figure legends. 


\section{Results}

\section{Number of cells responding}

Previous work has shown that the kinetic parameters governing global calcium signals generated in cultured cerebellar astrocytes, screened with high throughput imaging methods, did not show any clear dependence on agonist concentration or agonist type (James et al. 2011). In contrast, we observed that the number of cells responding to a given agonist (ATP, glutamate or histamine) appeared to show clear concentration dependence. To quantify this, we measured the percentage of cells responding to a stimulus in each well of a multiwall plate, and calculated the mean percentage of responding cells for all wells that were treated with the same stimulus (18 wells per agonist concentration).

The percentage of cells responding showed a concentration-dependent increase with agonist concentration, for ATP, glutamate and histamine (Fig 1A,B). However, the maximal percentage of cells varied substantially between agonists: at the highest concentration tested $(1 \mathrm{mM})$, ATP triggered $\mathrm{Ca}^{2+}$ signals in $85 \%$ of cells, whereas glutamate only triggered responses in $37 \%$ and histamine $46 \%$ of cells. The agonists therefore differ in the efficacy with which they can trigger a global $\mathrm{Ca}^{2+}$ elevation in astrocytes.

These features could be accounted for by two hypotheses. First, the concentration-responsiveness may reflect heterogeneity in cell sensitivity. In this scenario, increasing agonist concentration would recruit more and more cells as the threshold for triggering a cell-wide response was breached (NB the observation that the vast majority of cells exhibit a $\mathrm{Ca}^{2+}$ signal in response to high affinity pharmacological agonists suggests that the existence of appreciable numbers of non-responders is unlikely; James et al. 2011). The second possibility is that all cells are equally sensitive, and the percentage of responding cells reflects the probability that any given cell will respond. In this scenario, the concentration-dependence will arise as the probability of any one cell responding increases with agonist concentration.

A method for discriminating between the foregoing possibilities would be to repetitively apply agonist to a population of cells at a submaximal concentration (leaving time for recovery between applications). If the percentage of cells responding reflects a continuum of sensitivities, then the same highsensitivity subpopulation of cells should respond each time. Alternatively, if cells have equivalent sensitivities, but respond in a probabilistic manner, then there would be variability in the identity of responding cells between applications (i.e. any cell could respond, and chance determines which ones do).

\section{A probabilistic basis for cellular responses}

We applied ATP to a population of astrocytes at a sub-maximal concentration $(0.1 \mu \mathrm{M})$ for $3 \mathrm{~min}$, three times in succession, with a 5 min washout period between each addition (Fig $2 \mathrm{~A}$ ). On each occasion, around $40 \%$ of cells responded with a global $\mathrm{Ca}^{2+}$ signal within the 3 min stimulation period (Fig 2B). However, the specific cells responding varied from addition to addition. We observed all cases: cells that responded on 0 , 1, 2 or 3 occasions (Fig 2A,C). These results are consistent with the second hypothesis outlined in the last section - that each cell has a chance of responding, and the probability of response depends on ATP concentration.

There is a danger with repetitive application of agonists in this manner that later $\mathrm{Ca}^{2+}$ responses are altered by preceding ones; phenomena such as receptor desensitization (or internalization), store depletion, or feedback loops (such as autophosphorylation), may change the dynamics of the later $\mathrm{Ca}^{2+}$ signals. To test for this, we compared the area under curve (integral of fold change, $\left.\left(F / F_{0}\right) \cdot s\right)$ of the spikes evoked by 0.1 
$\mu \mathrm{M}$ ATP for each stimulus. There was no detectible difference in this parameter over the three trials (Fig 2B).

The results suggest that astrocytes respond to agonists in a probabilistic manner, rather than by varying in sensitivity. For a model based purely on chance, where all cells are equivalent, then the distribution of the total population into the four possible response classes $(0,1,2$, or 3 responses) can be predicted. If $40 \%$ of cells respond to $0.1 \mu \mathrm{M} \mathrm{ATP}$, then the distribution of cells into the response classes $(0,1,2$, or 3 responses) would be $21.6 \%, 43.2 \%, 28.8 \%$ and $6.4 \%$, respectively. The observed distribution diverged from this ideal case, with fewer cells than predicted giving a single or two responses, and more cells than predicted giving three responses (Fig 2C).

We next assessed the response of the astrocytes to glutamate and histamine, which generate a response in a lower percentage of cells, to investigate whether the same probabilistic trend was evident (Fig $3 \mathrm{~A}, \mathrm{~B})$. For glutamate $(5 \mu \mathrm{M})$, around $30 \%$ of cells responded for the first two additions and, as for ATP, the number of responses observed covered all possibilities: $0,1,2$ or 3 events per cell. In contrast to ATP, however, the percentage of responding cells decreased for the third trial, and the area under the curve for glutamate responses progressively declined (Fig $3 \mathrm{~A}$ ). These results suggest that although glutamate operates probabilistically, there is detectable desensitization over the course of the trials. Histamine responses were similar to ATP. Over the three trials, around $12 \%$ of cells responded, and the cells that responded varied from trial to trial, but with no apparent desensitization between trials (Fig 3B).

Another potential complication in interpreting results is the capacity of astrocytes to sustain intercellular waves through gap-junctional coupling and paracrine signalling (Giaume and Venance 1998). This could result in the transient application of agonists leading to a signal initiated in one cell propagating into neighbouring cells, meaning response probability may be overestimated due to indirect coupling (although under our culture conditions, cells are not confluent and rarely exhibit long range calcium waves). To test for this directly, we applied $0.1 \mu \mathrm{M}$ ATP to the cells for $3 \mathrm{~min}$ as usual, followed by addition of $100 \mu \mathrm{M}$ of the gap junction blocker carbenoxolone (Rozental et al. 2001), and another $3 \mathrm{~min}$ transient application of ATP. The presence of carbenoxolone did not significantly alter the percentage of cells responding to ATP (51.3\% before and $53.7 \%$ after; $p=0.623$, Fisher's exact test, $n=298$ ), or the mean area under the curve for fluorescence change in responding cells $\left(240.4 \pm 4.10\right.$ before and $243.3 \pm 3.29\left(F / F_{0}\right) \cdot s$ after treatment; $p=$ $0.09,2$ Mann Whitney test, $n=160$ ), suggesting that gap junctional coupling did not detectibly affect responses under normal conditions. These results suggest that propagation of calcium responses between neighbouring cells is unlikely to significantly distort interpretation of the percentage of responding astrocytes.

Overall, this analysis suggests that although there is heterogeneity in sensitivity amongst the cells to the different agonists, each cell displays a given probability of responding to a low amplitude, transient stimulus.

\section{Gain modulation of response probability}

Many neuromodulators and neurotransmitters have been shown to trigger calcium signalling in astrocytes, directly or indirectly (Fiacco and McCarthy 2006). There is also a wealth of research demonstrating crosstalk between the calcium signalling apparatus and other second messenger signalling networks (Bruce et al. 2003; Clementi and Meldolesi 1997), perhaps best exemplified by the range of signals that converge on the Ins $\mathrm{P}_{3}$ receptor (Foskett et al. 2007). This suggests that coincident activation of neurotransmitter receptors 
coupled to calcium release and modulatory receptors coupled to pathways that affect calcium signalling could alter the probability of generating a global calcium response.

Endocannabinoid signalling mediates neuromodulation in many neuronal classes and many brain regions (Howlett et al. 2004). In astrocytes, activation of cannabinoid receptor type 1 (CB1R) has been linked to calcium responses (Navarrete et al. 2014). To test for modulation of response probability, we stimulated cells with $0.1 \mu \mathrm{M}$ ATP, with and without co-application of the CB1 agonist WIN 55,212-2 (WIN, $1 \mu \mathrm{M}$ ). When WIN was present (1 min preincubation), there was a significant increase in the percentage of cells responding to ATP with a global calcium signal (Fig 4A). For those cells that responded, treatment with WIN had no effect on the total cytosolic calcium flux, as the area under the curve of the responses was unaffected (Fig 4A). Washout of WIN, and subsequent challenge with ATP alone showed that the potentiation of probability was reduced, but still statistically significant (Fig 4A). This result suggests that WIN is able to act as a positive modulator of the probability of evoking a global calcium response in the astrocytes.

Nitric oxide (NO) signalling has been reported to affect multiple aspects of the calcium signalling network, including InsP $\mathrm{P}_{3}$ receptors (Cavallini et al. 1996; Komalavilas and Lincoln 1996; Rooney et al. 1996), ryanodine receptors (Stoyanovsky et al. 1997; Takasago et al. 1991), store-operated and non-store operated calcium entry channels (Li et al. 2003; Moneer et al. 2003), and many other elements of the calcium handling apparatus (Clementi and Meldolesi 1997). The nature of this modulation appears to vary between cell types and experimental conditions, with NO being able to activate or inhibit several of these targets. In astrocytes, NO has been shown to accelerate the reloading of calcium stores (Li et al. 2003), increase the rate and range of calcium wave propagation through gap-junctionally coupling networks of cells (Willmott et al. 2000), and increase the frequency of spontaneous calcium oscillations in cultured astrocytes at physiological temperatures (Schipke et al. 2008). Direct activation of calcium responses by NO has also been reported (Bal-Price et al. 2002). We tested the effects of NO on ATP responses, under similar conditions to WIN.

Co-administration of NO (with 1 min preincubation) and $0.1 \mu \mathrm{M}$ ATP led to a significant increase in the percentage of cells responding to the stimulus (Fig 4B). NO also significantly increased the area under the curve of the calcium responses (Fig 4B). In contrast to WIN, the enhancement due to NO fully reversed after washout, with the response to a third ATP stimulus returning to pre-treatment levels (Fig 4B).

To test whether these modulators alone are able to trigger calcium responses in astrocytes, we applied WIN and DETA/NO for $18 \mathrm{~min}$ (Fig 4C). WIN had no detectible ability to trigger calcium responses under these conditions (Fig $4 \mathrm{C}$ ), but addition of the NO donor DETA/NO $(100 \mu \mathrm{M})$ to the astrocytes triggered global calcium responses in approximately $50 \%$ of cells (Fig $4 \mathrm{C}$ ). However, these responses had a long latency (mean = $318 \pm 21 \mathrm{~s}$ ), which could indicate an indirect effect on calcium signalling rather than direct calcium influx or release from stores due to $\mathrm{NO}$ acting as an agonist. We repeated the experiment in the presence of an antagonist for $\mathrm{P} 2$ receptors (PPADS, $100 \mu \mathrm{M}$ ), which substantially reduced the number of NO-evoked responses (Fig $4 \mathrm{C}$ ). This result indicates that the long-latency spikes triggered by NO depend on $\mathrm{P} 2$ receptor activation - suggesting that $\mathrm{NO}$ is acting indirectly, by increasing the number of global calcium signals spontaneously occurring through release of ATP from the astrocytes. Accordingly, the positive modulation of calcium responses to transient ATP stimulation by WIN and DETA/NO is due to enhancement of $\mathrm{P} 2$ receptor-evoked responses, not direct release of calcium following CB1R or soluble guanylyl cyclase activation. 
In addition to the positive gain modulation exhibited by NO and CB1 receptors, we explored whether negative modulation could also be observed. A number of TRP channels have been reported in astrocytes (Verkhratsky et al. 2014), and linked to basal elevation of cytoplasmic calcium concentration (Shigetomi et al. 2013). Gadolinium is a broad spectrum blocker of TRP channels (Bouron et al. 2015), and so we tested the impact of this ion on the probability of generating a global response to ATP. Gd ${ }^{3+}$ applied 1 min before subsequent co-application with ATP caused a substantial reduction in the percentage of cells responding to ATP (Fig 5A). $\mathrm{Gd}^{3+}$ also reduced the total calcium flux (as measured by area under curve) in responding cells. This reduction in probability and magnitude of response was fully reversible after washout (Fig 5A).

Finally, we also tested for the possibility of crosstalk with the second branch of the phospholipase $C$ signalling pathway by applying the direct activator of protein kinase $C$, phorbol 12-myristate 13-acetate (PMA, $10 \mathrm{nM}$ ). PMA alone had no noticeable effect on calcium concentration, but co-application with ATP after 1 min substantially reduced the percentage of cells responding, and the area under the curve of the responding cells. In contrast to the reversible negative modulation exhibited by $\mathrm{Gd}^{3+}$, PMA persistently decreased astrocyte responsiveness to ATP after washout (Fig 5B).

\section{The origin of probabilistic responses}

Global calcium responses originate from the summation of underlying subcellular events. To understand the factors that determine the probability of a global signal arising from calcium puffs, we need to understand how the number, frequency, size and range of subcellular events vary in astrocytes, and so determine why the same submaximal treatment sometimes results in initiation of a global wave but sometimes fails (even within the same cell).

To explore this issue, we used high speed epifluorescence imaging to measure fluorescence across a whole cell with sufficient spatiotemporal resolution to capture all subcellular events. Although this approach does not allow detailed spatial resolution of puffs, in the manner of optical sectioning methods (Sanderson et al. 2014), its advantage is that the entire cell can be imaged, and so the full complement of puffs can be detected. Our goal was to use this strategy to identify the determining factor in transition from local calcium puffs to a global calcium wave.

Previous studies in a variety of cell types have proposed different mechanisms for how changes in puff parameters lead to wave initiation after agonist addition (Bootman et al. 1997; Parker et al. 1996; Tovey et al. 2001): puff amplitude could increase, the spatial range of individual puff events could expand (enhancing coupling between clusters of Ins $\mathrm{P}_{3}$ receptors), or the frequency of puffs could increase. In principle, any of these effects could result in formation of a wave nucleation site, or they may act to simply increase cytosolic calcium concentration above a threshold level that causes a generalized increase in InsP $\mathrm{P}_{3} \mathrm{R}$ open probability (Marchant et al. 1999; Yamasaki-Mann et al. 2013).

High speed imaging of astrocytes allowed subcellular calcium release events to be identified throughout the cell cytoplasm (Fig 6A,B). Typically, cells exhibited multiple release sites, at which multiple release events could be observed, and readily distinguished from baseline fluctuations and the downward drift associated with photobleaching under continuous illumination (Fig 6B). Puffs were resolvable at subcellular sites, despite the mean fluorescence change for the entire cell showing only minor baseline deflections (Fig $6 \mathrm{~B})$. To quantify the parameters of these calcium puffs, we developed an algorithm for identifying fluorescence changes that matched the time course of typical release events (Fig 6C; for details, see 
Materials and Methods section), and used it to analyse the number, spatial range, and amplitude of calcium puffs in the astrocytes.

Under resting conditions, in standard imaging buffer, astrocytes exhibited spontaneous calcium puffs that occurred with a mean frequency of $10.6 \pm 1.1 \mathrm{~min}^{-1}$ (median $7 \mathrm{~min}^{-1}$ ), had mean amplitude of $1.07 \pm 0.04$ fold $\Delta \mathrm{F}$ (median 1.06 fold $\Delta \mathrm{F}$ ), and mean area of $45.7 \pm 1.6 \mu \mathrm{m}^{2}$ (median $31.39 \mu \mathrm{m}^{2}$ ) calculated from 65 cells. Round puff morphology was typically observed with diameters of $7.6 \mu \mathrm{m}$ (mean) and $6.3 \mu \mathrm{m}$ (median).

To determine how puffs were changed in response to agonist stimulation, we treated the cells first with a buffer exchange $10 \mathrm{~s}$ after initiating image acquisition, and then imaged for a further $50 \mathrm{~s}$, to determine puff parameters under resting conditions. The same cells were then treated for a second time, with buffer containing $0.1 \mu \mathrm{M}$ ATP (Fig 7A-C). Cells were segregated into those that exhibited a global signal $\left(\Delta \mathrm{F} / \mathrm{F}_{0} \geq\right.$ 1.045 relative to baseline and increase detectable in the nucleus), and those that only exhibited subcellular responses (Fig 7A).

The distribution of puff amplitudes in cells without a wave $(-w)$ and cells that transitioned to a wave $(+w)$ were closely similar (Fig 7B). Puff amplitude was compared within each cell during treatment with buffer, and treatment with ATP (Fig 7B). No significant changes in amplitude were observed after ATP treatment regardless of whether a global calcium response occurred.

The distribution of puff areas was also similar for cells that transitioned and cells that did not (Fig 7C). As with amplitude, the area of puffs did not significantly change after treatment with ATP for either class of cell (Fig 7C). Collectively, the results suggest that changes in the amplitude and size of puffs are not determining factors in whether cells transition from local to global signalling regimes.

We next tested the influence of puff frequency on the probability of transition. We measured the cumulative frequency of puffs in cells treated first with buffer exchange alone, followed by $0.1 \mu \mathrm{M}$ ATP. For cells that underwent a transition to waves, we stopped counting puffs at the point that wave initiation occurred, as the widespread release of calcium during the rising phase of the wave could not be distinguished reliably from a torrential, widespread series of puff events (which is, in effect, the nature of the calcium-induced calcium release process that constitutes the wave; Bootman et al. 1997). A further rationale for this approach was that our goal was to determine the conditions that lead up to the point of transition, not the dynamics of cytoplasmic calcium after the tipping point had been breached.

The trajectory for cumulative puff events was similar for both classes of cells exposed to buffer initially (with the exception of a few outliers), suggesting that cells that transition in the presence of ATP were not especially "excitable" under resting conditions (Fig 8A,B). After treatment with ATP, there was a small increase in mean puff number in cells that did not initiate waves (Fig $8 \mathrm{~A}$ ), but this was not statistically significant ( $p=0.059$; Wilcoxon signed rank test), suggesting that puff frequency was not reliability changed by addition of submaximal ATP concentrations.

Despite this apparently undetectable effect on puff frequency, $0.1 \mu \mathrm{M}$ ATP caused the formation of a global wave in nearly half of the tested cells. However, even in those cells that exhibited global waves, the trajectory of puffs preceding the tipping point was not noticeably different from cells that did not transition (Fig 8B). The total number of puffs between agonist addition and initiation of a wave in cells exhibiting a global response ranged from 1 to 12 (mode 6 ), a range of values frequently obtained in cells that did not give global responses (Fig 8A,B). Accordingly, the absolute number of puffs over the time taken to reach wave initiation (and so, the baseline frequency of puffs), did not correlate with whether or not a global 
response occurred; it is not possible to predict from the trajectory of puffs whether or not a given cell is going to transition.

Finally, we examined the temporal structure of the puff events, to investigate whether a particular pattern of puffs could be identified that occurred commonly in cells that respond globally, but rarely in cells which do not. Puff events were assigned to $300 \mathrm{~ms}$ bins (approximately half the duration of a single puff; see Fig $6 \mathrm{C}$ ), and aligned with the mean fluorescence intensity for the whole cell and for the nucleus (Fig 9A-C). In cells exposed to two rounds of buffer exchange, the frequency of puffs did not appear to change before and after treatment, and the distribution of puffs appeared random over time, with only one or two puffs per bin (Fig 9A). For cells exposed to ATP which did not exhibit global signals, a similar pattern was observed. The total number of puffs occurring after treatment increased, but the typical number of puffs per bin again remained at one or two (Fig 9B). In contrast, for cells that exhibited global signals, the moment of initiation was commonly preceded by a single $300 \mathrm{~ms}$ time bin in which three or more puffs occurred synchronously (Fig 9C).

To test the predictive power of this synchronicity more directly, we found the maximum number of puffs/bin for non-responding and responding cells (Fig 10). 14 of 18 cells with waves had three or more synchronous puffs, whereas only 6 of 27 non-wave cells had three or more synchronous puffs (Fig 10 ).

To determine whether the spatial distribution of puff events influenced the probability of a global wave evolving, we determined the Euclidean distance between puff events (using the centroid of the region where fluorescence was suprathreshold) for all cells that exhibited three or more synchronous puffs. We plotted the minimum and maximum distance between puff sites at the moment of synchronous release, for cells that did or did not transition to global responses.

The analysis showed that there was no statistically significant difference in the minimum distance between puff sites in responding and non-responding cells, although the range of values was greater for responding cells (Fig 10C). In contrast, responding cells showed a statistically significant increase in the maximum distance between puff sites compared to non-responding cells (Fig 10C).

These results suggest that synchrony in puff events (occurring in different regions of the cell) - rather than amplitude, range or cumulative frequency - is the major determinant of the probability that an agonist will result in a global calcium response under submaximal stimulation conditions. 


\section{Discussion}

Astrocyte calcium signalling is widely perceived to be a mechanism by which these electrically-passive cells can make an active contribution to information processing within the brain (Araque et al. 2014; Nedergaard and Verkhratsky 2012). Despite decades of research into the potential for modulation of neuronal development, synaptic transmission and synaptic plasticity, there is still much about the computational properties of astrocyte calcium signalling that is poorly understood. In particular, a recent controversy concerns the equivocal impact of deletion of type $2 \mathrm{InsP}_{3}$ receptors on the neurophysiological roles in which astrocytes have been implicated, despite overt loss of somatic calcium responses in astrocytes. In hippocampus, basal synaptic transmission and induction of plasticity was apparently unaffected by loss of global calcium responses (Agulhon et al. 2010), but cholinergic-dependent long-term potentiation in both cortex (Takata et al. 2011) and hippocampus (Navarrete et al. 2012), require Ins $P_{3} R 2$-dependent calcium signals in astrocytes.

One explanation for apparently benign outcomes after deletion of $\mathrm{InsP}_{3} \mathrm{R} 2$ is that the spatial organization of calcium signals is crucial to the effectiveness of signal transduction, with $\operatorname{InsP}_{3} \mathrm{R} 2$-dependent somatic signals being distinct in function from near-membrane calcium signals, or other subcellular/microdomain responses (Araque et al. 2014; Di Castro et al. 2011; Grosche et al. 1999; Shigetomi et al. 2010; Srinivasan et al. 2015). Despite this recognition of the importance of spatiotemporal segregation, widespread somatic calcium signals are readily observed in vivo (Hirase et al. 2004; Nimmerjahn et al. 2009; Wang et al. 2006). The roles of these signals are not well understood, however, nor are the potential computational rules that govern their emergence. Here we have investigated the basis by which global signals evolve from subcellular events, and the consequences of such all-or-nothing responses for computation in the face of local, low amplitude or short lived stimuli.

\section{The origin of global calcium responses in astrocytes}

A hierarchy of calcium signalling has long been recognized in cell physiology (Berridge et al. 2000). Release of calcium from InsP $\mathrm{P}_{3} \mathrm{Rs}$ can range in space from a unitary "blip" (opening of a single InsP $\mathrm{P}_{3} \mathrm{R}$ channel), to puffs (release from clusters of channels), and waves that represent the coordinated coupling of adjacent clusters of $\mathrm{InSP}_{3} \mathrm{Rs}$ to result in a spread of release events at the wavefront that progresses through the cell. The mechanistic basis of the latter global calcium signals, and how they evolve from underlying elementary events, has been studied in many cell types (Bootman et al. 2001; Cheng et al. 1993; Falcke 2003; Marchant et al. 1999; Ruckl et al. 2015; Tovey et al. 2001). Increases in puff amplitude, puff frequency, and puff size have all been reported to follow agonist application, but the common consequence is that cytosolic calcium increases to a threshold that triggers the positive feedback mechanism of calcium-induced calcium release (Bootman et al. 1997).

This tendency results in a situation where immediately after stimulation, cells enter a stochastic phase of calcium signalling, where puff events summate, increasing the "calcium load" on the cytosol until the threshold for calcium-induced calcium release is reached and a wave initiates (Marchant and Parker 2001; Thul and Falcke 2004; Thul and Falcke 2006; Thul et al. 2009). This pushes the cell into a phase where a global signal progresses through the cell in an almost deterministic manner, and the Ins $\mathrm{P}_{3} \mathrm{Rs}$ are inactivated until local calcium concentrations fall once more. Such a bimodal signalling regime has been modelled, and shown to be the basis of variation in inter-wave intervals in cells challenged with tonic stimuli (Skupin et al. 2008; Thurley et al. 2014). 
Although calcium puffs have previously been reported in astrocytes (Koizumi et al. 2002), the factors determining transition from subcellular to global signals have not been determined. A detailed characterization of the parameters defining puffs in astrocytes could not be obtained with our imaging approach, because wide field epifluorescent imaging allowed high speed and high resolution imaging of the whole cell but with less spatial resolution than optical sectioning methods. This compromise was needed to capture events throughout the whole cell, and means that resolving low amplitude or fast events would be constrained relative to methods such as TIRF or confocal microscopy (Ellefsen et al. 2014). Our goal, however, was to count all puffs and so gain a sense of whether a particular pattern or sequence of puffs gives a high probability of transition to a global wave. We found that astrocytes are in some respects atypical in their subcellular responses.

The analysis showed that the frequency of puffs in astrocytes was low compared to several cell lines (Tovey et al. 2001; especially given the more limited measurement volume due to optical sectioning used in these other studies), and that puff size and amplitude were unaffected by agonist application (Fig 7). As a consequence, even after stimulation with ATP, the total number of puffs occurring remained sparsely distributed in time (Fig 9). This consistency in the spatiotemporal properties of puffs has the consequence that, under our recording conditions, no obvious build up in bulk cytoplasmic calcium concentration was observed: there appears to be no cumulative increase in calcium "load" that leads inexorably to wave evolution. Instead, the best predictor for wave initiation seems to be the occurrence of the synchronous release of calcium from three or more puff sites (Fig 10; with a $300 \mathrm{~ms}$ window for coincidence). This sudden concerted release appears to be the basis of the all-or-none trigger for a global signal.

Analysis of the spatial distribution of synchronous puffs indicated that an increase in the maximum distance between puff sites was correlated with a greater probability of wave initiation. This suggests that formation of a local hotspot of release from multiple neighbouring sites is unlikely to be the trigger for initiation of a global wave; instead the implication is that spatially segregated puff sites causing calcium elevation over a wider area of the cytoplasm triggers the threshold crossing that leads to coordinated calcium-induced calcium release throughout the cell.

As a final note, in common with other reports (Wu et al. 2014), the spatial range of calcium signals varied considerably - indeed some subcellular events occupied a substantial fraction of the whole cell volumes, raising a question as to how a boundary between subcellular and global signals could be defined. In our case, the time course of waves was clearly distinguishable from that of puffs, and we further discriminated on the basis of the whether the signal occupied a sufficient range so as to encompass the nucleus.

Nevertheless, it should be acknowledged that while stereotypical puffs and waves were the most abundant signal classes (and could be easily distinguished), there is a continuum of intermediate signals that bridge these broad categories in space and time.

\section{Probabilistic encoding of stimulus amplitude}

The principal consequence of an all-or-none signal based on the chance of several puffs occurring synchronously, is that the signal transduction from agonist application to global response is probabilistic. At high concentrations of ATP, probability is high, but for other agonists, the maximum probability appears much lower, indicating that agonist efficacy manifests as the probability that a global signal will initiate (Fig 1B). 
Furthermore, submaximal concentrations, or transient or local applications, would also be predicted to provoke a response with lower probability. As a consequence, even a single cell presented with an identical stimulus on multiple occasions only has finite chance of responding to any individual challenge. As this is likely to be the character of a stimulus encountered in vivo following synaptic release of transmitters or modulators, it seems necessary to consider stimuli to be encoded not as stereotyped and predictable responses, but as a probabilistic signal. Such signals obviously recur in neuroscience, with synaptic transmission being the classic example.

When considering the potential for astrocyte calcium signalling to be involved in information processing, the input-output relationship between synaptic release and global calcium responses would manifest as a response probability. In contrast, the generation of localized calcium signals may be more reliable (high probability), again distinguishing the two modes of signal transduction on a computational as well as mechanistic basis. Ultimately, the determinant for whether a global signal evolves is the coordinated progression of a wave through the cytoplasm. If our results relate directly to the in vivo situation, local signalling in the vicinity of synapses (where receptors are clustered; Arizono et al. 2012) will be transmitted to the cell interior only if diffusion of $\mathrm{InsP}_{3}$ and $\mathrm{Ca}^{2+}$ reaches ER store receptors and triggers the synchronous release of calcium from multiple puff sites.

Determining the applicability of results from primary cultures to the in vivo state is always challenging. Nevertheless, if the astrocytic cytoplasm acts essentially as an "excitable medium" for propagating calcium waves, it seems reasonable to assume that the factors governing summation of subcellular events into cell wide events could be common between the in vitro and in vivo states. That said, the morphology of the cell would also be a determining factor for wave propagation - and the difference between protoplasmic cultured cells and the more diffuse and ramified anatomy of astrocytes in vivo may well alter wave propagation trajectories. Interestingly, the analysis of puff spatial distribution suggests that puffs occurring synchronously at more distant sites increases the likelihood of transition to a global signal. In situ this may translate into global calcium signals becoming more probable if multiple local signalling events occur synchronously - for example if there is coordinated release from multiple synapses that are all ensheathed by the same astrocyte. From a computational perspective, this offers the potential for spatial summation of activity in the synaptic network by the astrocyte.

\section{Gain modulation of global signals}

A final consideration in understanding how probabilistic encoding can influence computation is that the response probability can be altered by stimuli that do not themselves cause calcium release. This modulation can be positive or negative, and transient or prolonged (Figs 4,5).

There are numerous examples of crosstalk between neuromodulators, such as nitric oxide and endocannabinoids, and calcium signalling. Modification of the pumps, channels, transporters and buffers of the calcium signalling "toolkit" (Berridge et al. 2000), could alter many of the properties of calcium puffs; in this case, presumably altering the likelihood of synchronous events or the conditions under which puff to wave transitions occur.

Gain modulation of this type has been described in situ, in hippocampal slices. Functional independence was demonstrated between Schaeffer collateral and alveus inputs to astrocytes, with selective engagement of glutamate and acetycholine receptors respectively. Co-stimulation of the inputs led to bidirectional, 
frequency-dependent modulation of astrocyte calcium responses, due to crosstalk between the signalling pathways (Perea and Araque 2005).

Gain modulation has also recently been described in vivo. Astrocyte somatic calcium responses in the cortex depend on release of noradrenaline from locus coeruleus projections (Ding et al. 2013; Espallergues et al. 2007), despite ex vivo responses being mediated by glutamate released during local network activity. A possible explanation for this discrepancy comes from Paukert et al. (2014) who showed that astrocytes in the visual cortex did exhibit global responses to local transmission, but the responses were markedly enhanced by synergistic noradrenergic transmission.

These results suggest that the frequency of global responses that constitute the major part of somatic calcium signals detected by intravital imaging methods is highly sensitive to crosstalk between signalling pathways, suggesting that arousal increases the probability of global signalling. This phenomenon also suggests a note of caution for experimental studies, where application of agonists that provoke a calcium response in glia may not be reflective of a direct link between the agonist and calcium mobilization, but rather, a change in the probability of spontaneous puffs (or puffs generated by tonic signals) evolving into global responses. 


\section{Acknowledgements}

We thank Laura Stannard for carrying out initial experiments, and Marleen Groenen for technical assistance with cell culture methods. The work was funded by the Biotechnology and Biological Sciences Research Council UK (BB/B500958/1) and the Leverhulme Trust (RPG-2012-628). The authors have no conflicts of interest to declare. 


\section{References}

Agulhon C, Fiacco TA, McCarthy KD. 2010. Hippocampal short- and long-term plasticity are not modulated by astrocyte $\mathrm{Ca} 2+$ signaling. Science 327:1250-4.

Araque A, Carmignoto G, Haydon PG, Oliet SH, Robitaille R, Volterra A. 2014. Gliotransmitters travel in time and space. Neuron 81:728-39.

Arizono M, Bannai H, Nakamura K, Niwa F, Enomoto M, Matsu-Ura T, Miyamoto A, Sherwood MW, Nakamura T, Mikoshiba K. 2012. Receptor-selective diffusion barrier enhances sensitivity of astrocytic processes to metabotropic glutamate receptor stimulation. Sci Signal 5:ra27.

Bal-Price A, Moneer Z, Brown GC. 2002. Nitric oxide induces rapid, calcium-dependent release of vesicular glutamate and ATP from cultured rat astrocytes. Glia 40:312-23.

Berridge MJ, Bootman MD, Roderick HL. 2003. Calcium signalling: dynamics, homeostasis and remodelling. Nat Rev Mol Cell Biol 4:517-29.

Berridge MJ, Lipp P, Bootman MD. 2000. The versatility and universality of calcium signalling. Nat Rev Mol Cell Biol 1:11-21.

Bootman MD, Berridge MJ, Lipp P. 1997. Cooking with calcium: the recipes for composing global signals from elementary events. Cell 91:367-73.

Bootman MD, Lipp P, Berridge MJ. 2001. The organisation and functions of local $\mathrm{Ca}(2+)$ signals. J Cell Sci 114:2213-22.

Bouron A, Kiselyov K, Oberwinkler J. 2015. Permeation, regulation and control of expression of TRP channels by trace metal ions. Pflugers Arch 467:1143-64.

Bruce JI, Straub SV, Yule DI. 2003. Crosstalk between cAMP and Ca2+ signaling in non-excitable cells. Cell Calcium 34:431-44.

Cavallini L, Coassin M, Borean A, Alexandre A. 1996. Prostacyclin and sodium nitroprusside inhibit the activity of the platelet inositol 1,4,5-trisphosphate receptor and promote its phosphorylation. J Biol Chem 271:5545-51.

Cheng H, Lederer WJ, Cannell MB. 1993. Calcium sparks: elementary events underlying excitationcontraction coupling in heart muscle. Science 262:740-4.

Clementi E, Meldolesi J. 1997. The cross-talk between nitric oxide and Ca2+: a story with a complex past and a promising future. Trends PharmacolSci 18:266-269.

De Pitta M, Volman V, Berry H, Parpura V, Volterra A, Ben-Jacob E. 2012. Computational quest for understanding the role of astrocyte signaling in synaptic transmission and plasticity. Front Comput Neurosci 6:98.

Di Castro MA, Chuquet J, Liaudet N, Bhaukaurally K, Santello M, Bouvier D, Tiret P, Volterra A. 2011. Local $\mathrm{Ca} 2+$ detection and modulation of synaptic release by astrocytes. Nat Neurosci 14:1276-84.

Ding F, O'Donnell J, Thrane AS, Zeppenfeld D, Kang H, Xie L, Wang F, Nedergaard M. 2013. alpha1Adrenergic receptors mediate coordinated $\mathrm{Ca} 2+$ signaling of cortical astrocytes in awake, behaving mice. Cell Calcium 54:387-94.

Edelstein A, Amodaj N, Hoover K, Vale R, Stuurman N. 2010. Computer Control of Microscopes Using $\mu$ Manager: John Wiley \& Sons, Inc.

Ellefsen KL, Settle B, Parker I, Smith IF. 2014. An algorithm for automated detection, localization and measurement of local calcium signals from camera-based imaging. Cell Calcium 56:147-56.

Espallergues J, Solovieva O, Techer V, Bauer K, Alonso G, Vincent A, Hussy N. 2007. Synergistic activation of astrocytes by ATP and norepinephrine in the rat supraoptic nucleus. Neuroscience 148:712-23.

Falcke M. 2003. On the role of stochastic channel behavior in intracellular Ca2+ dynamics. Biophys J 84:4256.

Fiacco TA, Agulhon C, McCarthy KD. 2009. Sorting out astrocyte physiology from pharmacology. Annu Rev Pharmacol Toxicol 49:151-74.

Fiacco TA, McCarthy KD. 2006. Astrocyte calcium elevations: properties, propagation, and effects on brain signaling. Glia 54:676-90.

Foskett JK, White C, Cheung KH, Mak DO. 2007. Inositol trisphosphate receptor Ca2+ release channels. Physiol Rev 87:593-658. 
Giaume C, Venance L. 1998. Intercellular calcium signaling and gap junctional communication in astrocytes. GLIA 24:50-64.

Grosche J, Matyash V, Moller T, Verkhratsky A, Reichenbach A, Kettenmann H. 1999. Microdomains for neuron-glia interaction: parallel fiber signaling to Bergmann glial cells. NatNeurosci 2:139-143.

Haydon PG. 2001. GLIA: listening and talking to the synapse. Nat Rev Neurosci 2:185-93.

Hirase H, Qian L, Bartho P, Buzsaki G. 2004. Calcium dynamics of cortical astrocytic networks in vivo. PLoS Biol 2:E96.

Howlett AC, Breivogel CS, Childers SR, Deadwyler SA, Hampson RE, Porrino LJ. 2004. Cannabinoid physiology and pharmacology: 30 years of progress. Neuropharmacology 47 Suppl 1:345-58.

James LR, Andrews S, Walker S, de Sousa PR, Ray A, Russell NA, Bellamy TC. 2011. High-throughput analysis of calcium signalling kinetics in astrocytes stimulated with different neurotransmitters. PLoS One 6:e26889.

Khakh BS, Sofroniew MV. 2015. Diversity of astrocyte functions and phenotypes in neural circuits. Nat Neurosci 18:942-52.

Kimelberg HK. 2010. Functions of mature mammalian astrocytes: a current view. Neuroscientist 16:79-106.

Koizumi S, Saito Y, Nakazawa K, Nakajima K, Sawada JI, Kohsaka S, Illes P, Inoue K. 2002. Spatial and temporal aspects of $\mathrm{Ca} 2+$ signaling mediated by $\mathrm{P} 2 \mathrm{Y}$ receptors in cultured rat hippocampal astrocytes. Life Sci 72:431-42.

Komalavilas P, Lincoln TM. 1996. Phosphorylation of the inositol 1,4,5-trisphosphate receptor. Cyclic GMPdependent protein kinase mediates CAMP and CGMP dependent phosphorylation in the intact rat aorta. J Biol Chem 271:21933-8.

Li N, Sul JY, Haydon PG. 2003. A calcium-induced calcium influx factor, nitric oxide, modulates the refilling of calcium stores in astrocytes. J Neurosci 23:10302-10.

Marchant J, Callamaras N, Parker I. 1999. Initiation of IP(3)-mediated Ca(2+) waves in Xenopus oocytes. EMBO J 18:5285-99.

Marchant JS, Parker I. 2001. Role of elementary $\mathrm{Ca}(2+)$ puffs in generating repetitive $\mathrm{Ca}(2+)$ oscillations. EMBO J 20:65-76.

Moneer Z, Dyer JL, Taylor CW. 2003. Nitric oxide co-ordinates the activities of the capacitative and noncapacitative Ca2+-entry pathways regulated by vasopressin. Biochem J 370:439-48.

Navarrete M, Diez A, Araque A. 2014. Astrocytes in endocannabinoid signalling. Philos Trans R Soc Lond B Biol Sci 369:20130599.

Navarrete M, Perea G, Fernandez de Sevilla D, Gomez-Gonzalo M, Nunez A, Martin ED, Araque A. 2012. Astrocytes mediate in vivo cholinergic-induced synaptic plasticity. PLoS Biol 10:e1001259.

Nedergaard M, Verkhratsky A. 2012. Artifact versus reality--how astrocytes contribute to synaptic events. Glia 60:1013-23.

Nimmerjahn A, Mukamel EA, Schnitzer MJ. 2009. Motor behavior activates Bergmann glial networks. Neuron 62:400-12.

Parker I, Choi J, Yao Y. 1996. Elementary events of InsP3-induced Ca2+ liberation in Xenopus oocytes: hot spots, puffs and blips. Cell Calcium 20:105-21.

Patrushev I, Gavrilov N, Turlapov V, Semyanov A. 2013. Subcellular location of astrocytic calcium stores favors extrasynaptic neuron-astrocyte communication. Cell Calcium 54:343-9.

Paukert M, Agarwal A, Cha J, Doze VA, Kang JU, Bergles DE. 2014. Norepinephrine controls astroglial responsiveness to local circuit activity. Neuron 82:1263-70.

Perea G, Araque A. 2005. Properties of synaptically evoked astrocyte calcium signal reveal synaptic information processing by astrocytes. J Neurosci 25:2192-203.

Ransom B, Behar T, Nedergaard M. 2003. New roles for astrocytes (stars at last). Trends Neurosci 26:520-2.

Rooney TA, Joseph SK, Queen C, Thomas AP. 1996. Cyclic GMP induces oscillatory calcium signals in rat hepatocytes. J Biol Chem 271:19817-25.

Rozental R, Srinivas M, Spray DC. 2001. How to close a gap junction channel. Efficacies and potencies of uncoupling agents. Methods Mol Biol 154:447-76.

Ruckl M, Parker I, Marchant JS, Nagaiah C, Johenning FW, Rudiger S. 2015. Modulation of elementary calcium release mediates a transition from puffs to waves in an IP3R cluster model. PLoS Comput Biol 11:e1003965. 
Rusakov DA. 2015. Disentangling calcium-driven astrocyte physiology. Nat Rev Neurosci 16:226-33.

Sanderson MJ, Smith I, Parker I, Bootman MD. 2014. Fluorescence microscopy. Cold Spring Harb Protoc 2014:pdb top071795.

Scemes E, Giaume C. 2006. Astrocyte calcium waves: what they are and what they do. Glia 54:716-25.

Schipke CG, Heidemann A, Skupin A, Peters O, Falcke M, Kettenmann H. 2008. Temperature and nitric oxide control spontaneous calcium transients in astrocytes. Cell Calcium 43:285-95.

Shigetomi E, Jackson-Weaver O, Huckstepp RT, O'Dell TJ, Khakh BS. 2013. TRPA1 channels are regulators of astrocyte basal calcium levels and long-term potentiation via constitutive D-serine release. J Neurosci 33:10143-53.

Shigetomi E, Kracun S, Sofroniew MV, Khakh BS. 2010. A genetically targeted optical sensor to monitor calcium signals in astrocyte processes. Nat Neurosci 13:759-66.

Skupin A, Kettenmann H, Winkler U, Wartenberg M, Sauer H, Tovey SC, Taylor CW, Falcke M. 2008. How does intracellular Ca2+ oscillate: by chance or by the clock? Biophys J 94:2404-11.

Srinivasan R, Huang BS, Venugopal S, Johnston AD, Chai H, Zeng H, Golshani P, Khakh BS. 2015. Ca(2+) signaling in astrocytes from Ip3r2(-/-) mice in brain slices and during startle responses in vivo. Nat Neurosci 18:708-17.

Stoyanovsky D, Murphy T, Anno PR, Kim YM, Salama G. 1997. Nitric oxide activates skeletal and cardiac ryanodine receptors. Cell Calcium 21:19-29.

Takasago T, Imagawa T, Furukawa K, Ogurusu T, Shigekawa M. 1991. Regulation of the cardiac ryanodine receptor by protein kinase-dependent phosphorylation. J Biochem 109:163-70.

Takata N, Mishima T, Hisatsune C, Nagai T, Ebisui E, Mikoshiba K, Hirase H. 2011. Astrocyte calcium signaling transforms cholinergic modulation to cortical plasticity in vivo. J Neurosci 31:18155-65.

Thul R, Falcke M. 2004. Stability of membrane bound reactions. Phys Rev Lett 93:188103.

Thul R, Falcke M. 2006. Frequency of elemental events of intracellular $\mathrm{Ca}(2+)$ dynamics. Phys Rev E Stat Nonlin Soft Matter Phys 73:061923.

Thul R, Thurley K, Falcke M. 2009. Toward a predictive model of Ca2+ puffs. Chaos 19:037108.

Thurley K, Tovey SC, Moenke G, Prince VL, Meena A, Thomas AP, Skupin A, Taylor CW, Falcke M. 2014. Reliable encoding of stimulus intensities within random sequences of intracellular Ca2+ spikes. Sci Signal 7:ra59.

Tovey SC, de Smet P, Lipp P, Thomas D, Young KW, Missiaen L, De Smedt H, Parys JB, Berridge MJ, Thuring J and others. 2001. Calcium puffs are generic InsP(3)-activated elementary calcium signals and are downregulated by prolonged hormonal stimulation to inhibit cellular calcium responses. J Cell Sci 114:3979-89.

Verkhratsky A, Orkand RK, Kettenmann H. 1998. Glial calcium: homeostasis and signaling function. Physiol Rev 78:99-141.

Verkhratsky A, Reyes RC, Parpura V. 2014. TRP channels coordinate ion signalling in astroglia. Rev Physiol Biochem Pharmacol 166:1-22.

Wang X, Lou N, Xu Q, Tian GF, Peng WG, Han X, Kang J, Takano T, Nedergaard M. 2006. Astrocytic Ca ${ }^{2+}$ signaling evoked by sensory stimulation in vivo. Nat Neurosci 9:816-23.

Willmott NJ, Wong K, Strong AJ. 2000. A fundamental role for the nitric oxide-G-kinase signaling pathway in mediating intercellular $\mathrm{Ca}(2+)$ waves in glia. JNeurosci 20:1767-1779.

Woods NM, Cuthbertson KS, Cobbold PH. 1986. Repetitive transient rises in cytoplasmic free calcium in hormone-stimulated hepatocytes. Nature 319:600-2.

Wu YW, Tang X, Arizono M, Bannai H, Shih PY, Dembitskaya Y, Kazantsev V, Tanaka M, Itohara S, Mikoshiba $\mathrm{K}$ and others. 2014. Spatiotemporal calcium dynamics in single astrocytes and its modulation by neuronal activity. Cell Calcium 55:119-29.

Yamasaki-Mann M, Demuro A, Parker I. 2013. Cytosolic [Ca2+] regulation of InsP3-evoked puffs. Biochem J 449:167-73. 


\section{Figure Legends}

Figure 1: Percentage of cells responding to receptor agonists. A) Representative traces of Fluo-4 fluorescence in two astrocytes stimulated with $1 \mu \mathrm{M}$ ATP (left panel), $10 \mu \mathrm{M}$ glutamate (middle panel) or 10 $\mu \mathrm{M}$ histamine (right panel). For all agonists cells responding to the same stimulus with or without a global response are presented. B) Aggregate data of the percentage of astrocytes that exhibit a global response against agonist concentration for ATP, glutamate and histamine (as indicated). Data are mean \pm s.e.m. from 18 wells from nine 96-well plates of cultured cerebellar astrocytes (where each well contains several hundred cells).

Figure 2: Response of astrocytes to repetitive stimulation. A) Representative traces of Fluo-4 fluorescence intensity for five individual cells, illustrating the range of response characteristics observed. ATP $(0.1 \mu \mathrm{M})$ was added repetitively for $3 \mathrm{~min}$ (bars), with $5 \mathrm{~min}$ wash intervals. B) Aggregate data of percentage of cells exhibiting a global response (left panel) and the mean ( \pm s.e.m.) area under curve for detected responses (right panel) for 217 cells. No significant differences were detected in \% response (Fisher's exact test) or AUC (Kruskal-Wallis test with Dunn's correction for multiple comparisons) between the three additions of ATP. C) Distribution of cells into 0,1 , 2, or 3 global responses evoked by ATP (black bars), in comparison to predicted distribution due to chance alone (white bars).

Figure 3: Probabilistic responses to glutamate and histamine. A) Representative traces (upper panels) and aggregate data (lower panels) for astrocytes stimulated repetitively with $5 \mu \mathrm{M}$ glutamate (bars). ${ }^{* * *} \mathrm{p}$ $<0.0001$ for \% response (Fisher's exact test) and AUC (Kruskal-Wallis test with Dunn's correction for multiple comparisons) for comparison to first response; $n=508$. B) Representative traces (upper panels) and aggregate data (lower panels) for astrocytes stimulated repetitively with $10 \mu \mathrm{M}$ histamine (bars). No significant differences were detected in \% response (Fisher's exact test) or AUC (Kruskal-Wallis test with Dunn's correction for multiple comparisons) between the first, and second or third additions of histamine; $n=415$.

Figure 4: Positive gain modulation of global responses. A) Representative traces (upper panels) of cells repetitively stimulated with $0.1 \mu \mathrm{M}$ ATP (filled bars), with $1 \mu \mathrm{M}$ WIN 55,212-2 present for 1 min before and during the second stimulation (open bar). Aggregate data (lower panels) for \% of responding cells and mean area under curve ( \pm s.e.m). ${ }^{* * *} p<0.0001$ for \% response (Fisher's exact test), relative to the first ATP stimulus; $n=1322$. B) Representative traces (upper panels) of cells repetitively stimulated with $0.1 \mu$ M ATP (filled bars), with $100 \mu \mathrm{M}$ DETA/NO present for $1 \mathrm{~min}$ before and during the second stimulation (open bar). Aggregate data (lower panels) for $\%$ of responding cells and mean area under curve ( \pm s.e.m). ${ }^{* * *} p<0.0001$ for \% response (Fisher's exact test) and AUC (Kruskal-Wallis test with Dunn's correction for multiple comparisons), relative to the first ATP stimulus; $n=650$. C) Representative traces of astrocytes exposed to WIN 55,212-2 alone (upper trace) and DETA/NO alone or in the presence of $100 \mu$ M PPADS (lower traces) for $18 \mathrm{~min}$ (bars). Right panel: percentage of cells exhibiting global calcium responses in cells exposed to WIN alone $(n=464), D E T A / N O$ alone $(n=439)$ or cells exposed to DETA/NO in the presence of PPADS $(n=$ 373). ${ }^{* * *} p<0.0001$ relative to DETA/NO alone (Fisher's exact test).

Figure 5: Negative gain modulation of global responses. A) Representative traces (upper panels) of cells repetitively stimulated with $0.1 \mu \mathrm{M}$ ATP (filled bars), with $2 \mu \mathrm{M} \mathrm{Gd}{ }^{3+}$ present for 1 min before and during the second stimulation (open bar). Aggregate data (lower panels) for $\%$ of responding cells and mean area under curve $\left( \pm\right.$ s.e.m). ${ }^{* * *} p<0.0001$ for \% response (Fisher's exact test) and AUC (Kruskal-Wallis test with Dunn's correction for multiple comparisons), relative to the first ATP stimulus; $n=641$. B) Representative traces (upper panels) of cells repetitively stimulated with $0.1 \mu \mathrm{M}$ ATP (filled bars), with $10 \mathrm{nM}$ PMA present 
for $1 \mathrm{~min}$ before and during the second stimulation (open bar). Aggregate data (lower panels) for \% of responding cells and mean area under curve $\left( \pm\right.$ s.e.m). ${ }^{* * *} p<0.0001$ for \% response (Fisher's exact test) relative to the first ATP stimulus. ${ }^{*} p=0.012$ for AUC of second stimulus compared to first and ${ }^{*} p=0.024$ for AUC of third stimulus compared to first stimulus (Kruskal-Wallis test with Dunn's correction for multiple comparisons); $\mathrm{n}=227$.

Figure 6: Spontaneous calcium puffs detected in unstimulated cultured astrocytes. A) Widefield image of a representative cerebellar astrocyte loaded with calcium indicator Oregon Green 488 BAPTA-1. Overlaid ROIs (radius $=0.65 \mu \mathrm{m}$ ) are centred on puff site regions as detected by a bespoke puff detection algorithm. Scale bar $=10 \mu \mathrm{m}$. B) Normalized fluorescence changes within regions of detected puff sites and whole cell trace from the unstimulated representative cell in (A). C) Overlay of normalized fluorescence changes in 30 individual detected puffs from 6 unstimulated cells, aligned to fluorescence peak (mean in bold).

Figure 7: Area and amplitude characterisation of puffs from ATP-stimulated astrocytes. A) Representative traces of whole cell changes in fluorescence intensity over time of cells treated with $0.1 \mu \mathrm{M}$ ATP. Cells were classified into subpopulations that did not (ATP $-w$ ) or did (ATP $+w)$ transition to a global wave response. Arrows indicate the time of solution exchange. Puff amplitude (B) and area (C) data from two consecutive 60 s periods of image acquisition. In all first runs (Buffer), cells are unstimulated and in second runs (ATP), cells are stimulated with $0.1 \mu \mathrm{M}$ ATP. Comparisons of Buffer vs ATP are by histogram of all puff data from all cells and mean data from within the same cell across both runs. Statistical tests of Buffer vs ATP amplitudes and areas showed no significant differences, Wilcoxon signed-rank test. Data totals: ATP (- w), 21 cells, 223 puffs (Buffer), 280 puffs (ATP); ATP (+w), 280 puffs (Buffer), 480 puffs (ATP).

Figure 8: Cumulative puff counts in ATP-stimulated astrocytes. Trajectory of cumulative puff events detected in the same cells over two consecutive 60 s periods of image acquisition. In all first runs (Buffer), cells are unstimulated. In the second run (ATP) cells are stimulated with $0.1 \mu \mathrm{M}$ ATP. A) Puff counts from cells whereby ATP failed to induce transition to a global calcium wave (ATP - w). Right panel: comparisons of total puff counts in each cell (grey line and symbol). B) Puff counts up until the point of transition from cells that transitioned to a global wave following ATP stimulation (ATP $+w$ ). Right panel: comparisons of total puff counts in each cell (grey line and symbol), recorded up to the time of transition in run 2 (with the matched time in run 1). Number of cells analysed: $21($ ATP $-w)$ and $17($ ATP $+w)$ cells. Statistical tests of Buffer vs ATP total puff counts showed no significant differences: $p=0.059$ (ATP $-w$ ); $p=0.28$ (ATP $+w$ ); Wilcoxon signed-rank test.

Figure 9: Analysis of puff intensity in unstimulated vs ATP-stimulated astrocytes. Representative traces of whole cell/nuclear changes in fluorescence intensity and corresponding puff intensity data within the same cells. Data from 3 representative cells shown for A) unstimulated; B) ATP stimulated but no transition to global calcium wave $(-w)$ and C) ATP stimulated and transitioned to global wave $(+w)$. Dashed lines indicate 3 puff threshold. Bottom panels: Aggregate puff intensity data. Number of cells analysed for aggregate data: 12 (Buffer), 21 (ATP -w) and $17($ ATP $+w)$. Bin width $=300 \mathrm{~ms}$.

Figure 10: Spatial spread and counts of synchronous puffs in unstimulated and ATP stimulated astrocytes. A) Widefield images of representative cerebellar astrocytes loaded with calcium indicator Oregon Green 488 BAPTA-1. Overlaid is the localization and coverage of puff regions detected within a single time bin (300 ms duration) that contained the maximum number of synchronous puff events recorded over the timecourse. Synchronous puff overlays for ATP $(+w)$ cells are from time bins prior to time of transition to wave. Scale bar $=10 \mu \mathrm{m}$. B) Proportions of each cell population containing $\geq 3$ synchronous puff events in a single time-bin. Total cells analysed: 12(Buffer), 21(ATP $-w$ ) and $17($ ATP $+w)$. C) Maximum and minimum 
distances between puff centres in all cells that exhibited three or more synchronous events, for cells that did not transition to a global response ( $-w$, open symbols) and cells that did transition ( $+w$, filled symbols). Values for each cell are shown as grey squares, with mean ( \pm s.e.m.) as circles. ${ }^{*} p=0.0197$; Mann Whitney test. 


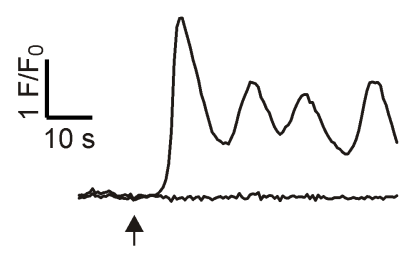

$1 \mu \mathrm{M}$ ATP

B

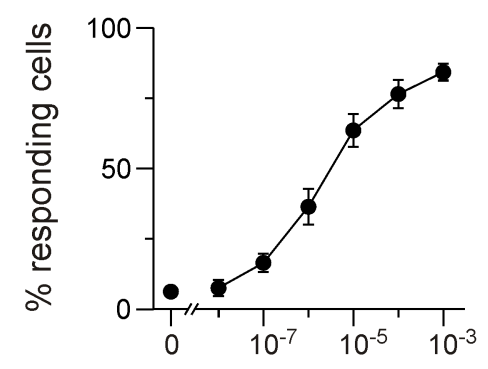

[ATP] (M)

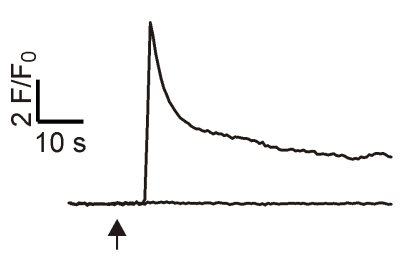

$10 \mu \mathrm{M}$ Glu

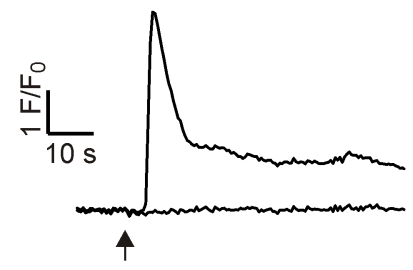

$10 \mu \mathrm{M}$ His

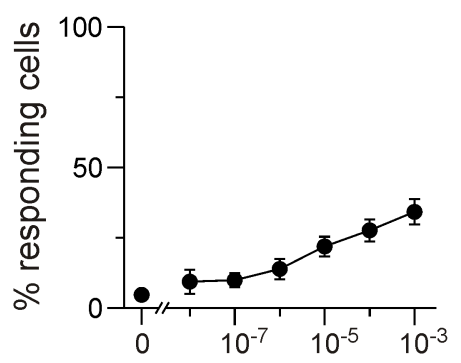

[Glu] (M)

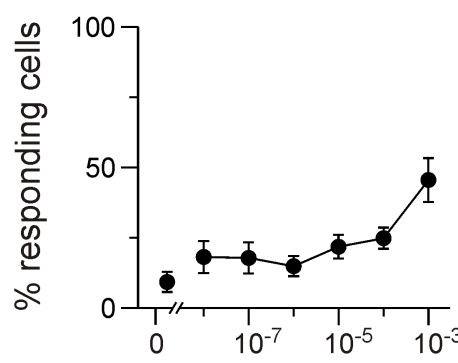

[His] (M) 


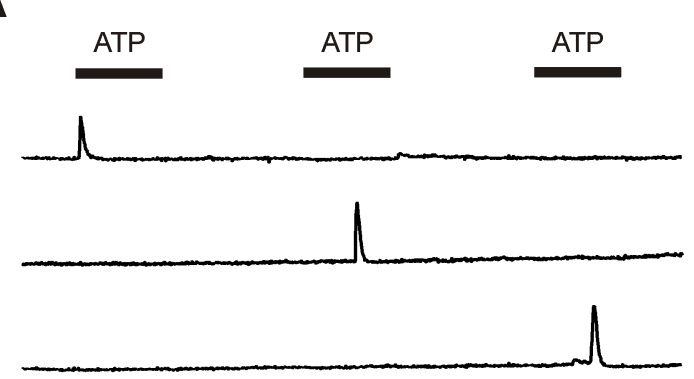

B
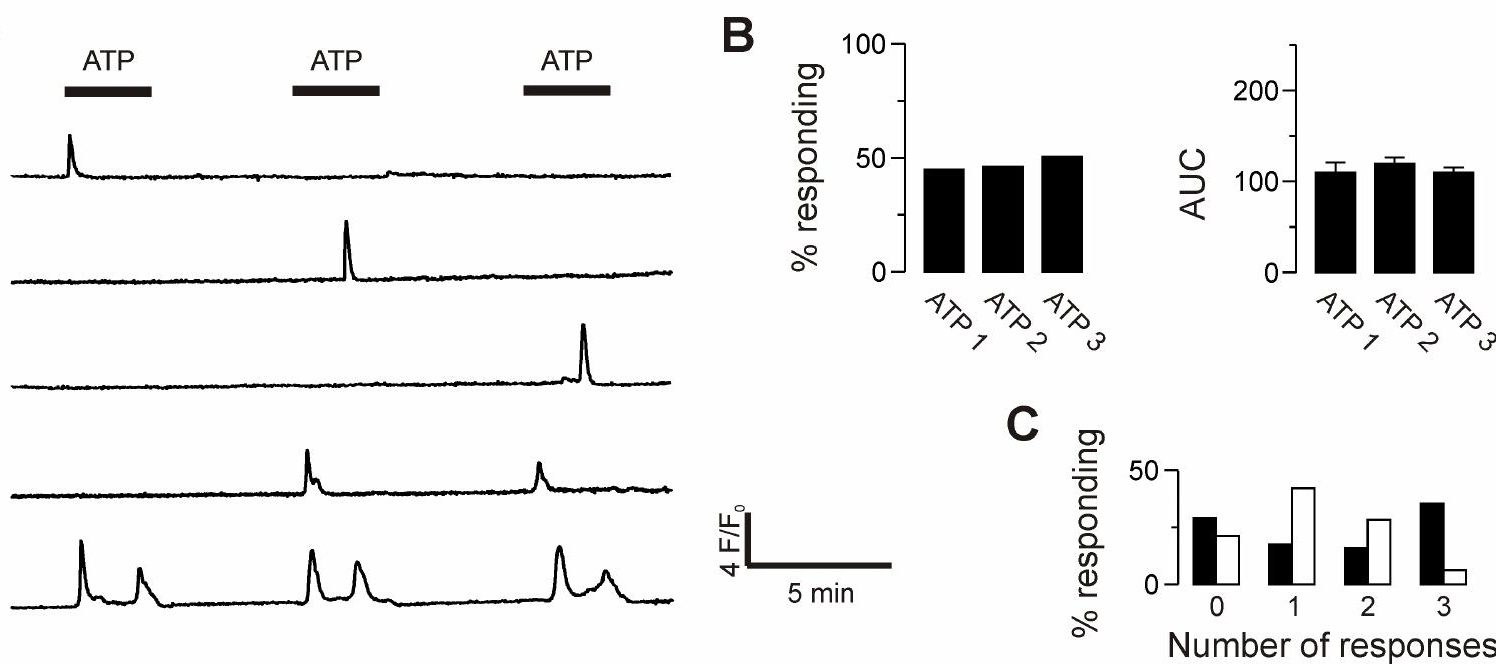
ATP
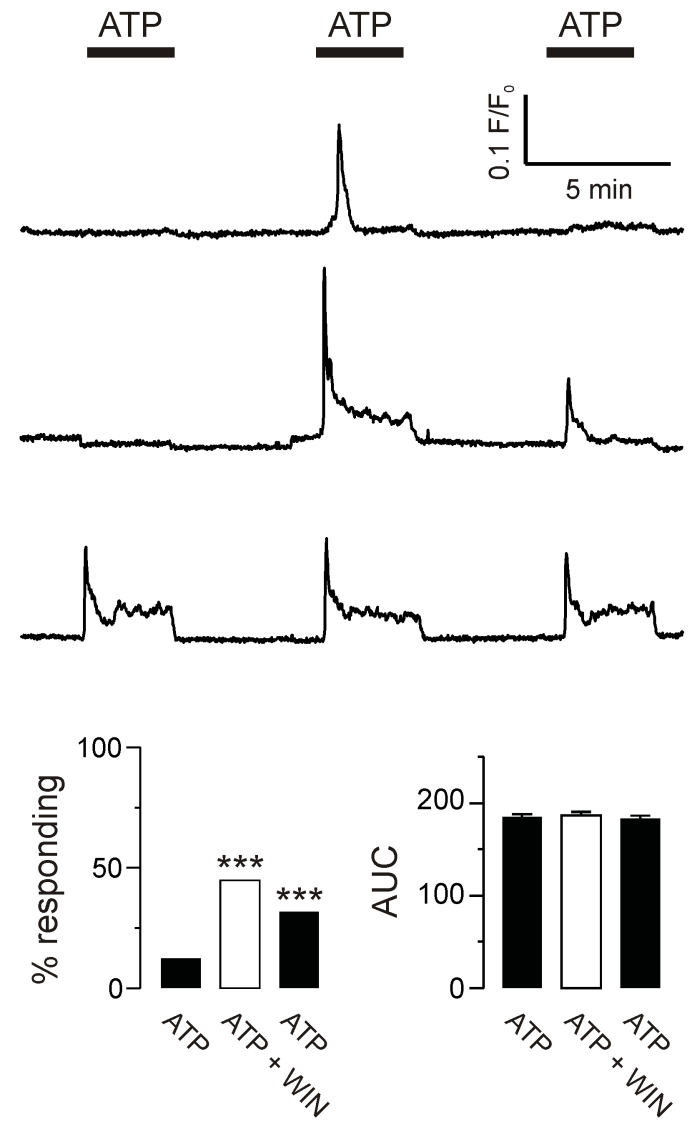

$1 \mu \mathrm{M}$ WIN 55,212-2

$100 \mu \mathrm{M}$ DETA/NO (0.7 $\mu \mathrm{M} \mathrm{NO})$

+ PPADS
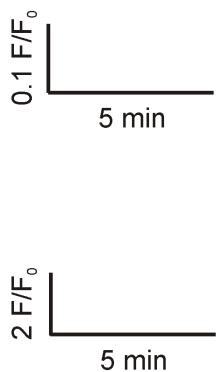

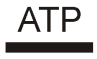

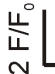

$5 \min$
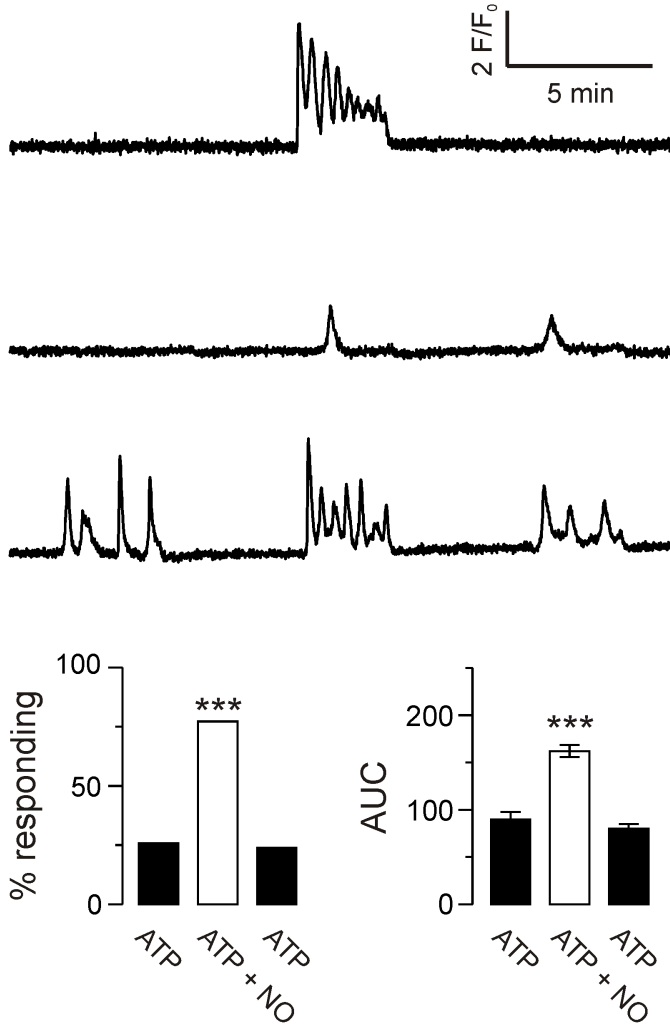

1

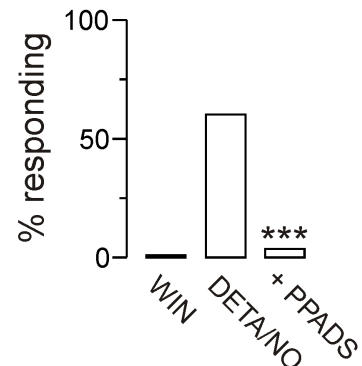




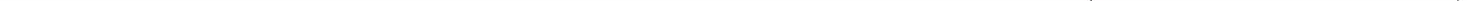




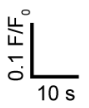

\section{2}

3

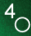

10

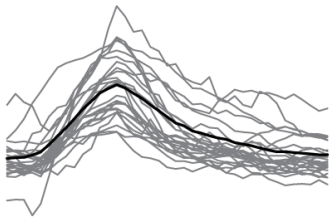

1

1

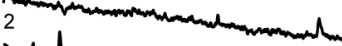
3 . 4

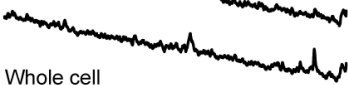
cell

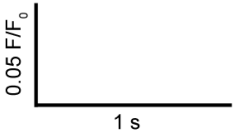




\section{A}

ATP (- w)

$\sqcup^{\circ} \quad$ B

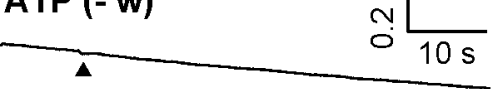

ATP (+ w)

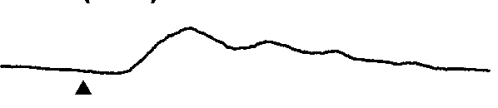

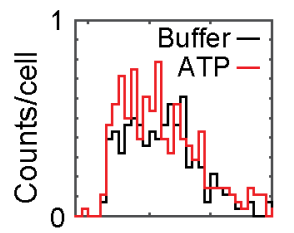

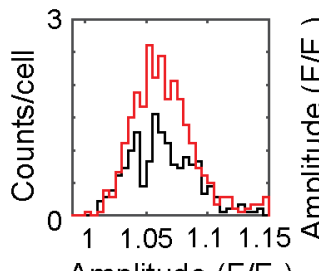

Amplitude $\left(F / F_{0}\right)$

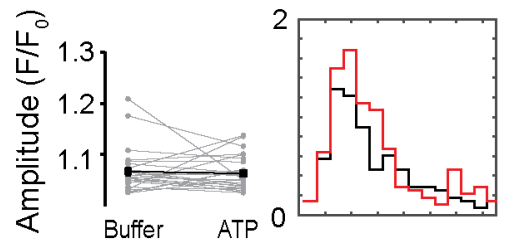

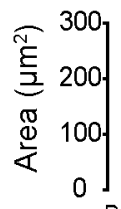

Buffer

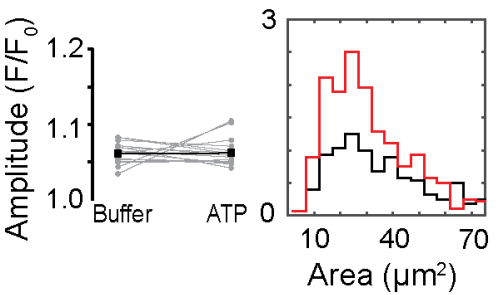

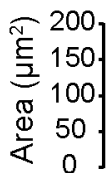

Buffer

ATP 


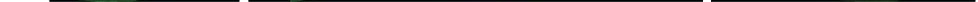

$\frac{1}{3}$
$\frac{1}{6}$
$\frac{1}{4}$
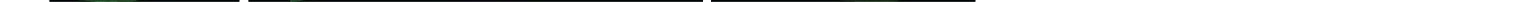

C

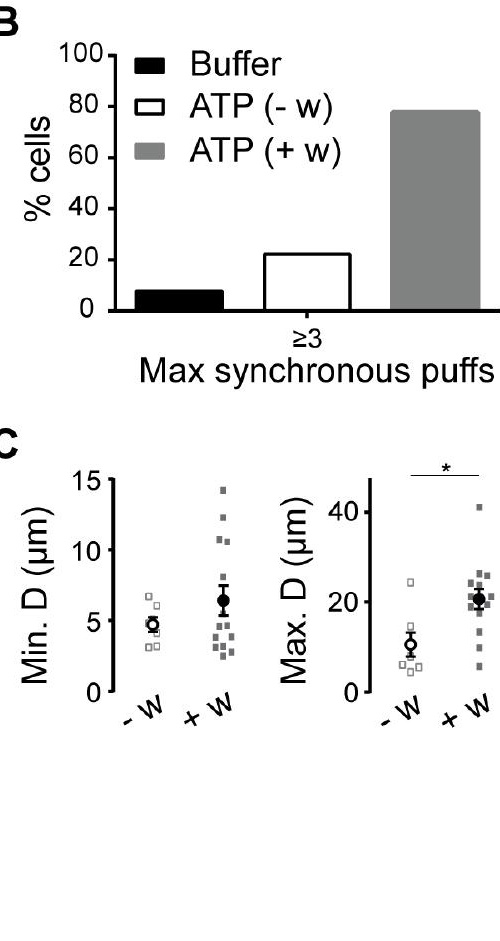

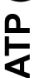

